\title{
Nursing Honor Societies: Past, Present, and Future
}

Michelle Dellaria Doas ${ }^{*}$, Kathleen Spadaro and Emily Stevens

Chatham University, Pittsburgh, PA, USA

*Corresponding author: Michelle Dellaria Doas, Associate Professor, Chatham University, Pittsburgh, PA, USA, Tel: 412-365-1188; E-mail: MDoas@Chatham.edu Received date: April 29, 2014, Accepted date: June 12, 2014, Published date: June 16, 2014

Copyright: (C) 2014 Doas MD, et al. This is an open-access article distributed under the terms of the Creative Commons Attribution License, which permits unrestricted use, distribution, and reproduction in any medium, provided the original author and source are credited.

\begin{abstract}
Honor societies have been a valued tradition among academia dating back to 1776 . Traditionally, honor societies have evolved as a means of recognizing academic excellence, leadership, service and scholarship. As a result, various disciplines including nursing have inducted students into respective honor societies over the past several hundred years. The proliferation of online education programs have raised issues related to the continuance of recognizing academic excellence in similar ways as traditional brick and mortar institutions. As a result, this article explored past, present and future trends for Honor Societies as educational programs and delivery formats continue to evolve.
\end{abstract}

Keywords: Honor societies; Bestowing honor; Higher education

\section{Introduction}

Honor Societies have been in existence for several hundred years. They are a time honored tradition among academic institutions for acknowledgement of student academic excellence. However, growing application of new educational information technologies has created a changing academic climate. A new population of nontraditional online students has emerged that defy past precedents of bestowing honor on great achievement. Yet those well deserving students require recognition both as individuals and as representative of their chosen profession. As such, Honor Societies will inevitably adjust ensuring continued outstanding academic recognition. The purpose of this article is to review past and present trends for Honor Societies as well as discuss needs for future direction.

\section{Background}

\section{Past}

The United States has a long standing history of identifying superior learners for their accomplishments in higher education settings. The oldest national academic honor society, Phi Beta Kappa, was established at the College of William and Mary in 1776. It was founded by five students during the American Revolution to recognize academic excellence and advance liberal arts and sciences both on the University and in society. By 1925, with the growing number of honor societies, a national certifying agency for college and university honor societies, the Association of College Honor Societies (ACHS), was formed. The ACHS was developed to maintain the integrity and purpose of national and international honor societies as well as set the standards for organizational excellence and for scholastic eligibility for the various categories of membership: general, specialized, leadership, freshman, and two-year honor societies [1,2].

The ACHS (2014) defines an honor society as "An association of primarily collegiate chapters whose purposes are to recognize and encourage high scholarship and/or leadership achievement in some broad or specialized field of study". Honor societies promote student excellence in scholarship and leadership with a specialized focus during the undergraduate and graduate years of education. Membership is generally awarded on an annual basis with criteria involving grade point average, class rank, and length of time in the academic program. Induction ceremonies celebrate the new member's achievement of honor society recognition and these students often retain membership for their lifetime.

These same standards are upheld and used among Bachelor's, Master's, and Doctoral level nursing students whom academically excel. The honor society for nursing, Sigma Theta Tau International (STTI), has been in existence since 1922. Their history identified six student nurses from the Indiana University Training School for Nurses, who birthed the Honor Society of Nursing, Sigma Theta Tau International. These founders are often referred to as the "Sigma Sisters" and include: Dorothy Garrigus Adams, Elizabeth Russell Belford, Edith Moore Copeland, Marie Hippensteel Lingeman, Elizabeth McWilliams Miller and Mary Tolle Wright. It is documented that these six founding student nurses were nearing the end of a very challenging clinical experience and academic term. Testimonials reflect they envisioned an honor society enveloped in recognizing knowledge formation which would transform the art of nursing into a science.

STTI became a member of the Association of College Honor Societies in 1959 and embraces the same quality and standards (Association of College Honor Societies, 2012). According to STTI (2005), a nursing honor societies main focus is to recognize an individual's academic and/or professional achievements. Joining an academic honor society traditionally allows for recognition to the individual's scholastic, professional achievements, and leadership potential.

The international nursing honor society membership has grown globally to more than 500 chapters in more than 85 countries. Each of these chapters are attached to an institution of higher education that provides nursing education to students for a baccalaureate degree or higher. There are two specific entry levels into STTI. These levels include academic and professional accomplishments. Historically, academic membership is based on a student's GPA during undergraduate or graduate nursing education. Professional 
membership includes achievements including research, publications, leadership, clinical practice and education (STTI, 2005). Induction into an honor society such as STTI signifies that an individual excels academically and/or professionally in his or her profession. Additionally, inclusion often includes demonstrated excellence along with the potential for leadership advancement within the profession [3-6].

\section{Present}

With emerging information technologies, the academic classroom has been forever changed. Higher education that was once based entirely in a traditional on ground classroom setting is now adjusting to meet the growing population of nontraditional students by providing online learning environments. Growth of online learning has been significant. Recent surveys results indicated that $69 \%$ of higher education leadership sees online learning as vital for institutional sustainability making this the highest percentage of online learning strategies within the past decade. Furthermore, of those institutions surveyed, $77 \%$ noted the online educational environment to be equivalent or better that the traditional on ground course delivery. The number of students enrolled in one or more online courses has increased by 570,000. This accounts for approximately 6.7 million or $32 \%$ of all students in higher education. As such, it is important to recognize that there are many nontraditional students enrolled in these courses. Online learning has provided a flexibility that permits learners to stay in one location, maintain their place of employment, and yet advance their career opportunities through continued education. To date, no significant difference has been demonstrated between traditional and nontraditional students [7]. Studies also indicate that online learners can develop their own community through their distance learning process $[8,9]$. Having and maintaining a community is vital for learning processes, networking, and furthering scholarship in the professional role.

Online nursing education has been a successful method for obtaining continuing post-licensure training for license and certification renewal. However, it has also become a means to reach nurses across the United States who have the desire to pursue further education in their field but are limited by work demands, family needs, and time limits. The American Association of Colleges of Nursing (AACN) surveys nursing programs periodically to identify new patterns and directions in nursing education. In their 2013 report, distance education was trending upward with $85.2 \%$ of RN-toBaccalaureate programs providing some online learning in their curriculums and $34.9 \%$ programs fully online. Similar trends were seen in the Master of Science in Nursing (MSN) and Doctor of Nursing Practice (DNP) programs, with $85.5 \%$ and $90.3 \%$ respectively delivered with some online learning and $19.4 \%(\mathrm{MSN})$ and $20.4 \%$ (DNP) fully online (AACN, 2013).

Projections indicate that the employed nursing work force will increase by $26 \%$ from 2.74 million in 2010 to 3.45 million in 2020 . Additionally, there will be a need to replace 495,000 positions creating the potential for 1.2 million open nursing positions that need to be filled by 2020 (Nursing shortage Fact Sheet AACN). Furthermore, only half of all nurses are educated at the baccalaureate or graduate level. This is problematic since research indicates that patient outcomes are better when cared for by a baccalaureate prepared nurse and graduate level nurses are needed to fill the faculty role (Nursing shortage fact sheet AACN). The Institute of Medicine (IOM) report
2011 called for nurses to achieve higher levels of education. These health care system demands lead to an increased need for online nursing education to meet the currently practicing nurse's needs for flexibility around work and family life.

Historically, professional organizations that provide support, continuing education, professional identity, and credentialing offer a small component online with networking through face-to-face meetings and conferences. The majority of nurses who return to school for their advanced degree (RN-BSN, MSN, and DNP, PhD) also work and manage family life with limited time and resources to stay connected to their professional organization(s). This creates the challenge for educational institutions on how to provide recognition for academic excellence for their online students and help them maintain professional growth. Additionally, there is a strong institutional need for alumni to stay connected both to the academic facility and to other graduates even when they are geographically located across the country. Therefore, one would anticipate that online nursing programs will continue to grow given the call for nurses at all educational levels. This creates a need to uphold as well as recognize the profession's academic excellence among both traditional and nontraditional students.

Phi Kappa Phi, founded in 1897, is one of the few national honor societies that recognized the needs of online learners by publishing the White Paper: Phi Kappa Phi and the Distance Learner (2007). Through their research, the Phi Kappa Phi task force uncovered significant findings that noted honor societies in general were not addressing the needs of online learners. In fact, when queried none of the honor societies had methods in place to meet the challenges imposed through online learning or distance education. Therefore, Phi Kappa Phi chose to use the College of Honor Societies Standards and Guidelines (2005) that challenged academic institutions to meet the needs of distance learners by offering them the same services as students who attend campus, resulting in the inclusion of distance learners into their honor society.

In addition, technology has exponentially added to communication and networking among groups of people. Like most professions, nursing organizations and societies have developed websites to inform their members of advancement in their field, scholarship, educational opportunities, conferences, and events. The websites are in addition to the traditional organizational activities. Sigma Theta Tau International has 508 chapters, all of which have a supporting website for their members. One of STTI's chapters, Phi Gamma, is set apart from the others. Phi Gamma was developed as a virtual chapter for inclusion of nurse leaders who are not affiliated with an academic institution. This chapter developed from a need to reach any nurse who did not have the opportunity to join STTI during their academic education. Although it is an innovative way to reach out and provide recognition to outstanding nurses within the profession, this chapter cannot provide its members a sense of community through institutional connection and a shared academic connection. Furthermore, this virtual chapter does not address the needs of current online nursing programs that have students who excel and are worthy of academic recognition.

Chatham University's nursing program identified the need to acknowledge academic excellence in their three fully online RN-BSN, MSN, and DNP programs. Driven to ensure nurses who live in the United States, Puerto Rico, Canada, or other countries due to military deployment to have the same academic recognition and encouragement the faculty were inspired to initiate a nursing honor 
Citation: Doas MD, Spadaro K, Stevens E (2014) Nursing Honor Societies: Past, Present, and Future. J Nurs Care 3: 172. doi: 10.4172/2167-1168.1000172

Page 3 of 3

society. The nursing honor society was developed as a fully online honor society offering educational opportunities, networking, and scholarship advancement to its members. One example includes a virtual poster presentation session featuring student scholarly work. After two years in existence as a university student organization, the nursing honor society has been accepted as Chi Zeta, the $508^{\text {th }}$ chapter of Sigma Theta Tau International.

\section{Future}

There are multiple needs and demands converging to challenge the academic institution that provides online education to nursing students. The surge of online education has grown significantly since 2002 (from 1.6 million to 6.1 million in 2010) and is acknowledged to be a critical component to the higher education institution's long-term strategic plan $[3,4]$. One of the calls for Distance Learning Administrators is to provide access to honor societies and professional organizations [5]. A critical demand for increasing the nursing workforce by 2020 creates a challenge for nursing programs that struggle with faculty shortages and their ability to increase student enrollment. Online nursing programs are a mechanism to meet this challenge by allowing flexibility for both the student and the faculty. With the increase in online learning and the plethora of information technology, one has to ask-Why not create online honor society chapters that include both traditional and nontraditional students? Is it not time to create honor societies with a virtual or online component to recognize nursing student's academic excellence? To date, Chatham University has the first know STTI chapter that consists of its own current students and alumni that was created exclusively for online learners [6-11].

\section{Conclusion}

Honor societies are of the utmost importance for acknowledging exceptional student achievement. This acknowledgement should recognize both traditional on-ground and nontraditional online learners. Online programs offer flexibility to students including nurses who continue to work and raise a family while completing their degree. Although many nursing programs have a mission to prepare the student to function professionally, take leadership positions at work and in the community, and acknowledge the need for life-long learning in their profession, they may not have a means to recognize student academic excellence and provide for continued peer networking.

\section{Discussion}

Creating an honor society at the level of the institution as a means to become a STTI chapter is a way to meet this goal. It is time to recognize both traditional and non-traditional student academic achievement by creating an online honor society for nursing. This will uphold the time honored tradition for recognizing outstanding student educational excellence.

\section{References}

1. American Association of Colleges of Nursing (2013) Enrollment and Graduations in Baccalaureate and Graduate Programs in Nursing.

2. Association of College Honor Societies (2013) ACHS Membership Information: Definition of Honor Society.

3. Allen IE, Seaman J (2011) Going the distance: Online Education in the United States.

4. Allen IE, Seaman J (2013) Changing Course: Ten Years of Tracking Online Education in the United States.

5. McFarlane DA (2011) The leadership roles of distance learning administration (DLAs) in Increasing educational value and quality perceptions. Online Journal of Distance Learning Administration 4:1.

6. Carriuolo N (2002) The Nontraditional Undergraduate and Distance Learning: Is Higher Education Providing a Portal of Just a Keyhole to Social and Economic Mobility?

7. Phi Kappa Phi (2007) White Paper on the Distance Learner

8. Miller, Michael T, Lu Mei-Yan (2003) "Serving Non-Traditional Students in E-learning Environments: Building Successful Communities in the Virtual Campus" Education Media International 40: 163-169.

9. Swan K, SheaP (2005) The development of virtual learning communities. In Asynchronous Learning Network: The Research Frontier.

10. Sigma Theta Tau (2005) Tau Lambda at Large Chapter. Annual Presidential reports, 2002, 2003, 2004.

11. Sigma Theta Tau International (2012) Determining membership eligibility per STTI by laws. 